\title{
perifèria
}

Número 8, Junio 2008

www. periferia.name

\section{De la difusión de tópicos a las estrategias auto-reflexivas: el caso de la representación de las mujeres brasileñas en los medios de comunicación portugueses}

\author{
Luciana Pontes Pinto - Departament d'Antropologia social i cultural - UAB ${ }^{1}$
}

\section{Resumen}

En este artículo comento la representación de la alteridad en los medios audiovisuales, enfatizando la representación del "no-occidental", de las mujeres y de la inmigración. A partir de este panorama, analizo género y nacionalidad con el ejemplo de la representación de las mujeres brasileñas en los medios de comunicación portugueses. Concluyo este texto señalando distintas formas de representación de la alteridad que buscan ultrapasar los tópicos, en lo que se suele nombrar la reflexividad en la Antropología Visual.

Palabras clave: antropología social; migración; género; audiovisuales; alteridad.

\begin{abstract}
In this paper I comment on the representation of alterity at the audiovisual media, emphasizing the representation of the "no-occidental", of women and of immigration. Departing from this background, I analyze gender and nationality in the representation of Brazilian women at the Portuguese media. I conclude this text pointing to different forms of representation of alterity that try to overcome prejudices, in what is usually called the reflexivity in the Visual Anthropology.
\end{abstract}

Keywords: Social Anthropology; migration; gender; audio-visual; alterity.

Mientras hacía mi trabajo de campo sobre las migradas ${ }^{2}$ brasileñas en Lisboa, me encontré con diversas imágenes en que la "mujer brasileña" era la protagonista. Considerando que estas imágenes están influenciadas por la historia de la

\footnotetext{
${ }^{1}$ Enviar correspondencia a: pontes.luciana@gmail.com.

2 Tal y como Sipi y Araia (2005), prefiero la palabra migradas o migrados a "inmigrante", una vez que esta tiene connotaciones de transitoriedad y desarraigo - véase la critica realizada, entre otros, por Rodrigo Alsina (2006). Sin embargo, mientras tales autores hablan de inmigrados, prefiero el término migrado/as, una vez que el prefijo "in" habla desde la perspectiva del país receptor. Cuando la palabra "inmigrante(s)" aparezca entrecomillada, es para señalar que es ésta la palabra utilizada por el discurso comentado (de los medios de comunicación, por ejemplo) y relativizarla.
} 


\section{perifèria}

Número 8, Junio 2008

www.periferia.name

representación del "otro" ${ }^{3}$ y especialmente de la mujer periférica y racializada, en el presente trabajo realizo una reflexión sobre estos temas.

Este artículo está compuesto de tres partes. En la primera, busco antecedentes de la representación de la alteridad en los medios audiovisuales enfatizando la representación del "no-occidental", de las mujeres y de la inmigración. La segunda parte trata de ejemplificar lo expuesto en la primera parte a través de un estudio de caso de las representaciones sobre las mujeres brasileñas migradas en Portugal, analizando cuestiones relativas a género, nacionalidad y etnicidad. En la tercera parte, explico la aportación de algunos realizadores que se han volcado hacia la exploración menos estereotipadas de representar al "otro".

\section{El “otro", las mujeres y la inmigración en los audiovisuales}

En este tópico procedo a un breve resumen, orientado hacia los intereses del presente trabajo, de 1) la representación audiovisual de la alteridad comentada desde una perspectiva de la Antropología Visual, 2) la representación audiovisual de las mujeres desde una perspectiva de las teorías de género y 3) la representación de la inmigración en los medios audiovisuales.

\subsection{Algunas consideraciones sobre la representación audiovisual de la alteridad}

En este tópico introduzco algunas de las cuestiones respecto a la representación del "otro" en la Antropología Visual relevantes para el presente trabajo. A través del comentario sobre cómo tal representación surge en algunos de los productos

\footnotetext{
${ }^{3}$ Aunque no sea del ámbito de este trabajo una discusión completa sobre la alteridad, tema por si solo suficiente para una tesis entera, ésta no deja de ser una cuestión de cierta manera latente en esta exposición. Sin entrar en más detalles, se considera aquí el "otro" el que en otras partes ya se ha denominado el "no-blanco", el "no-occidental", etc. Es decir, a grandes rasgos, seria aquella gran mayoría de la población mundial que, en el sistema jerárquico del poder económico, político, racial, etc., con sus divisiones Norte/Sur, Blanco/Negro, Hombre/Mujer, etc., está en el lado dominado de estas relaciones. Sin embargo, esta definición no deja de ser problemática, porque supone un "nosotros" blanco, varón, occidental, etc. del cual sólo una elite forma parte. Así, como se puede ver, este mismo concepto de alteridad ha sido forjado a través de relaciones de poder. A falta de mejor concepto inteligible y sintético, utilizo éste con muchas reservas. Como se verá en el cuerpo del texto, intentaré, siempre que posible, prescindir de ello, utilizando más bien expresiones descriptivas; sin embargo, muchas veces no es posible, y acabo utilizando expresiones como: "Otro", "no-occidentales", mujeres "no-occidentales". También éstas aportan sus problemas, sin embargo, queda registrada la perspectiva desde donde son utilizados tales conceptos.
} 


\section{perifèria}

\section{Número 8, Junio 2008}

www. periferia. name

audiovisuales que frecuentemente son considerados como los precursores de la Antropología Visual, en este tópico se discute la relación entre forma y contenido y entre representación e ideología, y algunos de los problemas éticos que supone la representación del "otro".

El desarrollo de la fotografía y del cine etnográfico se produjo en un contexto de expansión territorial y económica que, con el desarrollo de los transportes y de cámaras portátiles, posibilitó el acceso y la documentación de áreas remotas. Así, entre otros, la cámara acompañó a exploradores, oficiales coloniales, etc. Como demuestran Hartmann, Silvester \& Hayes (1998), la fotografía va a ser un medio del poder colonial, en que el lenguaje fotográfico, usado como descripción, documentación, clasificación y legitimación de lugares y personas, va a ejercer importantes funciones represivas y distintivas, de control político-cultural y atribución de status. Así, una vez que el poder de representar estuvo en manos de una elite blanca europea, la representación audiovisual del "otro" estableció símbolos de modernidad versus primitivismo, civilización versus salvajismo, creando una imagen del "otro" consonante con las representaciones de éste en las categorías raciales y de alteridad del sistema simbólico etnocéntrico (Hartmann, Silvester \& Hayes, 1998; Rony, 1996).

La historia de la Antropología Visual empieza así en este marco de documentación colonial de un "otro" exótico: el propio Jean Rouch consideraba que la historia de la Antropología Visual empezó en 1901, con los primeros vídeos acerca de las danzas de los aborígenes australianos (Heider, 1995). Sin embargo, muchos consideran a Robert Flaherty (director de Nanook, película sobre los Inuit estrenada en 1922) como principal pionero del documental etnográfico ${ }^{4}$. Flaherty era un explorador, que hizo una película sobre la vida de los esquimales en un espíritu de documentación de estilos de vida en riesgo de desaparición y de representación del "otro" en un tono "buen salvaje" (Heider, 1995; Barnouw, 1983; Rony, 1996; Nichols, 1991). No obstante, independientemente de cuál haya sido el primero en

\footnotetext{
${ }^{4}$ Otro de los pioneros más importantes será Grierson, mencionado a continuación.
} 


\section{perifèria}

\section{Número 8, Junio 2008 \\ www.periferia.name}

hacer una película representando al "otro", para el presente trabajo importa más el contexto y el tipo de mirada que va a ser proyectada sobre el "otro".

Flaherty es un símbolo de la ambivalencia existente en la representación audiovisual del "otro". Por una parte, tales críticas tienen que ver con el periodo histórico en que se insertaban los críticos y cuál era la estética dominante en el género "documental" : mientras unos lo criticaron por mezclar realidad y ficción (en la época en que el documental era definido por documentalistas como Grierson por su "fidelidad a la realidad"), otros lo alabarían por el mismo motivo (en un contexto posterior en que tal paradigma se ha roto, como veremos a continuación). Sin embargo, otra crítica persistente, realizada por autoras/es como Rony (1996), considera la mirada de Flaherty como etnocéntrica, apuntando hacia una romantización del "otro" y su estilo de vida. Como veremos adelante en el apartado tres, esta autora sugiere que lo que hizo Flaherty no puede ser calificado como una mezcla entre realidad y ficción, sino que se trata, más bien, de un sistemático ocultamiento de las condiciones de producción de la película, que en todo momento fue publicitada como "auténtica".

En este sentido, quizás tal problemática sea más explícita en otras películas realizadas pocos años después. A posteriori del éxito de Nanook (1922), serán producidas varias películas imitando el género (Barnouw, 1983). Manteniendo el tema de los parajes lejanos y pueblos exóticos, vemos la producción de películas como Grass (1925) y Chang (1927). A su vez, siguiendo claramente este espíritu de la época, pero ya en los terrenos de la películas de acción, Tarzan de los monos

\footnotetext{
${ }^{5}$ La definición de documental es un tema bastante delicado, siendo objeto de un aguerrido debate en el campo audiovisual. Mientras algunos de los más influyentes fundadores de la tradición documentalista (como Grierson) defendían una concepción del documental como "espejo de lo real", posteriormente serán muchos los realizadores que van a cuestionar el status de verdad de la imagen documental. Este movimiento de auto-reflexividad en el documental, abogando por la fluidez de fronteras entre documental y ficción, va a proponer una serie de estrategias de subversión del formato convencional del documental: sea utilizando actores, sea haciendo ficción en un formato documental (el conocido "falso documental"), sea incorporando explícitamente el punto de vista del realizador, etc. Así, autores como Weinrichter (2004) prefieren el término no ficción para designar tal género cinematográfico. Mientras tal terminología por una parte despierta mi simpatía y puede que llegue incluso a usarlo para no repetir mil veces la palabra documental, es, sin embargo, también de cierto modo impreciso: tal movimiento de auto-reflexividad también propone a menudo la mezcla entre documental y ficción, de manera que el término no ficción acabaría negando tal mezcla.
} 


\section{perifèria}

Número 8, Junio 2008

www.periferia. name

$(1932)^{6}$ reconvierte el tema en una versión mucho más comercial. La imagen siguiente pertenece a la película Congorilla, de $1932^{7}$.

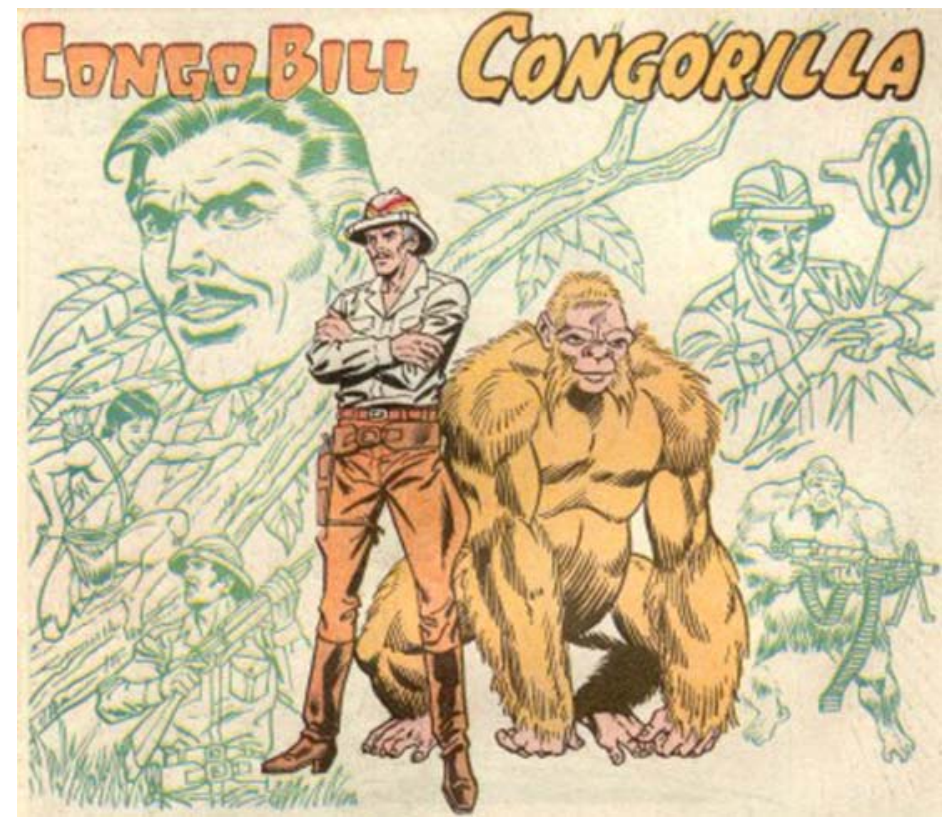

Fuente: http://www. moviegoods.com/movie product.asp?master movie id=20990

Como argumenta Rony (1996), todas estas películas van a contribuir para una representación del "otro" como salvaje, primitivo, exótico, constituyéndolo como espectáculo etnográfico para un público blanco occidental. Para Rony (1996), la representación audiovisual del "otro" en tal contexto opera a través de un mecanismo de "taxidermización", en que su imagen es utilizada para dar

\footnotetext{
${ }^{6}$ Este es el año de una de las películas Tarzan más conocidas del público, la primera con Johnny Weissmuller, el actor que ha interpretado tantas veces tal papel (veinte veces), que acaba siendo indisociable del personaje. Sin embargo existieron otros "Tarzanes" muy emblemáticos, como Gordon Scott. La primera película Tarzan es de 1918, dirigida por Scott Sidney.

${ }^{7}$ Aunque se pueda decir que todas estas obras reflejan la génesis de una historia de la representación audiovisual del "Otro", sería reduccionista no reconocer las diferencias entre ellas. Por ejemplo, aunque Nanook también fue un éxito comercial, se puede decir que es mucho más etnográfico que Tarzan, caso extremo de exotización de los territorios desconocidos y su estilo de vida.
} 


\section{perifèria}

\section{Número 8, Junio 2008}

www.periferia. name

verosimilitud a las representaciones colonialistas realizadas sobre este "otro" a quien no se atribuye historia ni se le otorga voz.

Respecto al cine etnográfico propiamente dicho, Karl Heider (1995) enfatiza la importancia de Gregory Bateson y Margaret Mead. Entre 1936 y 1939, Mead y Bateson realizarían un estudio en Bali $^{8}$ en que intentan desarrollar un método de empleo del filme y de la fotografía como parte integrante de la investigación antropológica. Tal proyecto es realizado a través del trabajo conjunto y simultáneo de fotógrafo y antropóloga, los cuáles, participando de una misma situación, procuraron describirla en dos soportes lingüísticos diferentes (el fotográfico y el discursivo) para, a través de la conjugación de ambos, ofrecer una descripción lo más completa y lo menos mediada posible.

Pese a que tal intento constituye una estrategia de representación del otro preocupada por la cuidadosa contextualización de cada fotografía, de los lugares y personajes, Rony (1996) también es extremamente crítica sobre él, en su ansia de documentación de estilos de vida en riesgo de desaparición. En este sentido, tal autora compara el proyecto de Mead con el "taxidermismo" cientificista de los antropometristas, en el sentido en que ambos van a acercarse al cuerpo del "nativo" con un gran apetito por los datos, en el caso de Mead, heredado de Boas: “...Like Regnault ${ }^{9}$, Mead thought that film could provide an important record of the ways of life of vanishing races; she also endorsed the idea that by collecting and examining an enourmous amount of film material, the anthropologist could make anthropology a science..." (Rony, 1996: 67).

Sin embargo, como ya he empezado a insinuar desde el principio de este tópico, el canon estético-estilístico mayoritario del género documental acabó siendo definido por Grierson, influyente miembro del "General Post Office" británico. Como explica Weinrichter (2004), su objetivo era “...establecer cierta imagen del documental como "utilitario, pedagógico e impersonal"..." (2004:31). Esta estética, que propuso

\footnotetext{
${ }^{8}$ Tal investigación resultaría en la publicación de Balinese Character y de seis filmes, estrenados en 1950.

${ }^{9}$ Fisiólogo y antroprometrista francés cuya obra, que consiste basicamente en el registro y análisis etnocéntrico de los movimientos corporales de los "salvages", es analizada por Rony (1996).
} 


\section{perifèria}

\section{Número 8, Junio 2008 \\ www. periferia. name}

un uso de la imagen como "espejo de lo real", está basada en una concepción renacentista de la imagen documental que niega u omite el carácter construido del acto de representar y la inevitable transformación de la realidad inherente al acto de representar (Dubois, 1986; Nichols, 1991). Así, el formato documental acabó anclándose en un status de verdad y en condiciones formales como la voz en off equivalente sonoro de la concepción de la imagen como espejo de lo real, con un narrador omnisciente que representa la "voz de la 'Historia'” (Nichols, 1991; Rosenstone, 1997).

Actualmente, el paradigma ético y estético propuesto por Grierson es bastante criticado. La concepción del documental (en la fotografía y en el cine) como un registro exacto de una situación real ha sido criticada y, así como la etnografía, pasa a ser vista desde un punto de vista parcial de una realidad contestada y plural. Aunque las diferencias entre documental y ficción han alimentado un debate antiguo, en el que precursores del documental como Grierson defendían la "superioridad moral" del documental por su compromiso con la realidad, recientemente la discusión ha cambiado de dirección, y muchos autores han enfatizado los elementos comunes a los dos géneros, empezando por considerar la imagen como una huella de la realidad, y no la realidad misma (Dubois, 1986, Nichols, 1991).

Esta autorreflexividad acerca del carácter naturalizante e ideológico de la concepción de la imagen como "espejo de lo real" va a abrir paso también a otras consideraciones tanto formales como éticas. Entre ellas, pasan a ser cuestionados tanto la autoridad etnográfica del realizador como qué representación se realiza del "otro". Sin embargo, sigamos analizando el carácter naturalizante e ideológico de la concepción de la imagen como "espejo de lo real", dejando el tema de la autorreflexividad en suspenso para ser retomado más adelante.

\subsection{Algunas contribuciones de los estudios de género al análisis de la representación audiovisual de las mujeres}

Este apartado se centra sobre la representación audiovisual de las mujeres, abordando especialmente como esta naturaliza el orden de género establecido. 


\section{perifèria}

\section{Número 8, Junio 2008}

\section{www. periferia. name}

Como veremos, existe un fuerte paralelismo entre la representación exótica del "otro" analizada en el apartado anterior y la representación audiovisual de la mujer: ambas se basan largamente en una representación naturalista y naturalizante (Hayward, 1996). A partir del establecimiento de esta conexión, procedo al tratamiento del tema de la representación de las "mujeres no-occidentales". Para ello, intento combinar, como propuso Mulvey (2001), esta perspectiva más psicoanalítica ${ }^{10}$ con una breve contextualización histórica del tema.

La representación audiovisual de las mujeres se basa en gran medida en las ideas predominantes en la representación androcéntrica de las mujeres en general: en ella, la alteridad de género es construida bajo la naturalización del sexo y de la identidad femenina, la concepción de femineidad se basa en los valores dominantes de lo que es el comportamiento deseable por parte de las mujeres, el cuerpo femenino es expuesto de una manera sexualizada, los personajes femeninos son la mayoría de veces secundarios y pasivos - o bien son castigados por no serlo (Rose, 2001; Ortner, 1996). Normalmente, son los hombres los protagonistas, siendo, a menudo, no sólo los sujetos de la acción, sino también los portadores del punto de vista $^{11}$ de la película.

Tal y como hemos visto respecto a la representación audiovisual del "otro", también la naturalización del androcentrismo en la representación audiovisual de la mujer opera muchas veces a través de una representación naturalista de los hechos, como nota Hayward (1996): “...Naturalism as an effect (...) places the spectator voyeristically. We take up the position of the mediating camera. The characters seem so natural, their dialogue or verbal interchanges so real, the setting and the mise-en-scène ${ }^{12}$ so totally realistic that an easy identification takes place. We are

\footnotetext{
10 Una primera cosecha del análisis de la representación de las mujeres en el cine por parte de los estudios de género incorporó a sus herramientas analíticas términos psicoanalíticos, como el concepto mismo de voyeurismo. Años más tarde se va a reconocer la necesitad de combinar esta tendencia con un análisis histórico (Mulvey, 2001).

${ }^{11}$ El punto de vista de la película es la perspectiva desde la cual se realiza la narrativa. Muchas veces coincide con la perspectiva del protagonista, pero también puede que el punto de vista sea el de un narrador omnisciente 0 , incluso, lo que es mucho menos habitual, existe la posibilidad de que se trate de una película coral, donde se contemplen varios puntos de vista.
}

12 Puesta en escena. 


\section{perifèria}

\section{Número 8, Junio 2008}

www.periferia.name

there alongside the characters. Take, for example, On the Waterfront (Elia Kazan, 1954) and the use of the diegetic audience ${ }^{13}$ to place us as one of the protagonist's entourage (Marlon Brando as Terry Malloy). The reality of what we see befor us, with which we identify, stitches us into the illusory nature of the representation so that it appears innocent, natural. In this way, naturalism has an ideological effect much like naturalizing..." (Hayward, 1996: 285).

Como vemos, este efecto naturalizante del "naturalismo" es lo mismo que hemos tratado en el apartado anterior bajo la designación "espejo de lo real". Mientras allá, la omisión de que todas las convenciones fílmicas son construidas, incluso en el documental, naturaliza el orden "racial" en un sentido bastante amplio, aquí sucede lo mismo respecto a género: la presentación de las desigualdades de género es representada como algo natural y, así como la puesta en escena parece absolutamente factible incluso en una película de ciencia ficción, también es muy normal que el protagonista de la trama, e incluso el espectador, sean un "hombre blanco europeo" y que las mujeres aparezcan como madres, esposas o hasta "chicas modernas" o prostitutas según una imagen bastante concreta de los valores que el patriarcado les asigna, de comportamiento, de corporalidad y de relaciones (Hayward, 1996; Rose, 2001, Mulvey, 1975).

Igualmente, el establecimiento de una mirada voyeurística hacia la mujer es especialmente importante en la representación esencializada en términos de género. Laura Mulvey (1975) es la autora de un texto breve pero fundamental en el análisis de la representación de las mujeres en el cine, el cual irá a definir algunos de los conceptos básicos utilizados en las teorías de género respecto a tal temática. Mulvey (1975) propone básicamente, apoyada en teorías psicoanalíticas, que la representación de las mujeres en el cine está construida para transformarlas en el soporte pasivo de una mirada voyeurística, un objeto para estimular el placer escópico del espectador varón. De esta manera, la representación de la mujer en el cine aparece marcada por esta erotización del cuerpo femenino, constituido así como objeto de deseo.

\footnotetext{
${ }^{13}$ Representación de una audiencia dentro del film.
} 


\section{perifèria}

\section{Número 8, Junio 2008}

\section{www.periferia. name}

Años más tarde, la propia Mulvey reconocería las limitaciones de esa tendencia de la cual fue fundadora. Pese a la importancia del psicoanálisis como herramienta analítica, la autora hace notar que la representación de las mujeres en la gran pantalla se encuentra relacionada con discursos de la femineidad en distintos contextos políticos y económicos. Las mujeres no serán solamente un espectáculo erótico para ser mirado, sino también sujetos a los cuales el sistema va a enviar sus mensajes de belleza y glamour no sólo en la dirección de una subjetivación como mujer, pero también como consumidoras del cine, de Hollywood, de los nuevos productos en el mercado y, especialmente, de America, del "american way of life" y, en el contexto analizado (de la guerra fría), del propio capitalismo. Así, Mulvey (2001) propone una teoría feminista del cine que abarque tanto la erótica y la estética de la mirada conformada por género desde una perspectiva psicoanalítica como desde una perspectiva histórica del cine como una industria relacionada con otras estructuras y contextos socio-económicos.

En un sentido similar, considero que la representación de las "mujeres nooccidentales" se encuentra relacionada tanto con el contexto en que surgió, como con los procesos de naturalización de género y de "raza", presentes tanto en la sociedad en general como en las representaciones audiovisuales. Como ya se subrayó anteriormente, las alteridades de género y de "raza" cuentan con características en común (e interrelacionadas). Quizás tal encuentro se dé especialmente en el ámbito de la sexualidad, en que tanto la sexualidad femenina como la sexualidad del "otro" son representadas como peligrosas, y, por lo tanto, requieren control.

La sexualización y exotización de las "mujeres no-occidentales" es un tema largamente desarrollado por las teorías de género, especialmente por aquellas también volcadas hacia el tema de la etnicidad, así como por los llamados estudios pos-coloniales. Como hemos visto anteriormente en Nash (2006), el discurso de ambas desigualdades es bastante similar tanto en supuestos (biologismo) como en funciones (justificación de las desigualdades fundadoras de la Europa moderna), compartiendo buena parte del imaginario del siglo XIX. Tanto la fotografía como el cine surgen en este contexto ideológico, y se nutren de él en sus construcciones de 


\title{
perifèria
}

\author{
Número 8, Junio 2008
}

www. periferia. name

la femineidad exótica.

El desarrollo de la fotografía y del cine está directamente vinculado a los procesos de modernización de las sociedades industriales. Tal y como nos explica Freund (2006), será la ascensión de la burguesía y su necesidad de afirmación identitaria a través de su representación visual, la condición social imprescindible que va a impulsar el desarrollo de la fotografía. Así, tal como anteriormente la pintura había retratado la aristocracia, la fotografía empieza dedicándose especialmente a los retratos de una burguesía emergente.

El mercado fotográfico se constituye a través de este filón de los retratos y, una vez consolidado, empieza a diversificarse admitiendo más variedad temática. Cuanto a la representación de las mujeres en la fotografía, el desnudo femenino será uno de los primeros temas a establecerse (Ewing, 1994). Una vez que este proceso de desarrollo inicial es marcado por la búsqueda de ampliación de las posibilidades comerciales del medio, se intenta impulsar un incremento del mercado consumidor de fotografías, que en un primer momento se encontraba bastante limitado a la curiosidad de algunos inventores, artistas, científicos y burgueses. Así, a partir 1850, se populariza el formato postal, dentro del cual tiene bastante éxito la comercialización de soft porn (Freund, 2006). En este contexto, siguiendo la iconografía pictórica dominante de la época, la representación de las mujeres era bastante exoticizada, siendo presentada desnuda entre sedas, ornamentos y objetos fetichizantes (Ewing, 1994).

En este mismo momento histórico, también se utiliza comercialmente la etnicidad como modelo de exoticidad femenina, como es el caso de la publicación de postales eróticas de mujeres negras destinadas principalmente a los soldados presentes en las áreas coloniales (Hartmann, Silvester \& Hayes, 1998:13). Así, tal y como comenta Ewing (1994): “...Muchas de las primeras fotografías de los pueblos 'exóticos' parecen haber sido inspiradas por lujuria, así como por el miedo, o al menos por una fascinación con su relativa desnudez. En las mentes de muchos fotógrafos europeos y sus clientes hombres, las mujeres negras africanas son primordialmente objetos de deseo, criaturas profundamente carnales, amorales y 


\section{perifèria}

\section{Número 8, Junio 2008 \\ www. periferia. name}

sumisas al poder superior del hombre blanco...". (Ewing, 1994: 247-249).

En este sentido, las mujeres "no occidentales" presentan una doble o incluso una triple alteridad, de género, de "raza" y de clase (Almeida, 2000; Parella, 2003). Las representaciones sobre estas mujeres se encuentran fuertemente marcadas por la asociación de las mujeres y muy especialmente las de "otras" culturas: 1) a la naturaleza, conteniendo elementos de irracionalidad, emotividad, descontrol y peligrosidad - especialmente respecto a la sexualidad (Rosaldo, 1974), y 2) a la domesticidad, abarcando atributos como la pasividad, el cuidado de los demás, la maternidad y la sumisión (Gil, 2002; Nash, 2006).

Como demostraré en el tópico sobre la representación de las mujeres migradas brasileñas en Portugal, estas imágenes de la "otra" heredadas del colonialismo14 son reelaboradas en el contexto de la inmigración, presentando cambios, pero manteniendo una importante carga de etnización y exoticización de las migradas. El hecho de que éstas son "inmigrantes" es asociado con la pertenencia a otro grupo étnico-nacional exótico, periférico, racializado y de una clase económica subalterna. Lo mismo es corroborado por Argote (2007) respecto a la representación de las mujeres migradas en el cine: “...Entre enero de 2000 y diciembre de 2002 se han estrenado en las salas de cine de Madrid 287 películas españolas. De entre ellas, una de cada cuatro (67 en total) contiene algún personaje extranjero; y de estos personajes la mujer inmigrante es, sin duda, la peor parada. No tiene voz; es prostituta en la mayoría de los casos; es malintencionada y su presencia en el filme se justifica como elemento desestabilizador que narrativamente "hay que" aniquilar

\footnotetext{
${ }^{14}$ Teniendo en cuenta que los estudios pos-coloniales son bastante controvertidos, aclaro un poco el argumento sobre las imágenes heredadas del colonialismo. Como explica Dijk, el discurso emanado por las elites conforman un racismo institucional duradero: “...el racismo contemporáneo en Europa no es una invención nueva, sino que continúa una larga tradición, y no está causado por la inmigración, sino por la descripción sistemáticamente negativa de los otros en las representaciones sociales a lo largo del tiempo..." (in Bastida, 2006:21). A través de este discurso, las clases y etnias dominantes simultáneamente ejercen el poder y legitiman el poder ejercido sobre las minorías étnicas. Asimismo, como demuestra Maataoui (en Bastida, 2006), la historia tiene un importante componente en la formación de una representación sobre el "Otro": a través del ejemplo de como los "árabes" son representados en España actualmente, nota como muy a menudo son hechas referencias a la reconquista, entre otros elementos que evocan imágenes centenarias sobre quienes son los "musulmanes", etc. (El entrecomillado relativiza las nociones de "árabes" y "musulmanes", que, como explica el mismo autor, son utilizadas con muy poco criterio en los medios).
} 


\section{perifèria}

\section{Número 8, Junio 2008}

\section{www. periferia.name}

o domesticar para una recuperación del equilibrio inicial. En alguna películas, simplemente están muertas, como la prostituta rusa en El alquimista impaciente, o van acabar muriendo enganchadas a los paraísos artificiales de la droga, como la hija de española y guerrillero colombiano en Olivia. En otras, y al estilo convencional de aquella "pretty woman" de Garry Marshall, aparecen junto a hombres españoles que rescatan a estas mujeres de la calle (o de la expulsión del país, o de la red de trata de blancas, o de la pobreza...) (...) Si las inmigrantes proceden de un país llamado "Tercer Mundo", son acalladas (como en Salvajes) o relegadas al murmullo (Poniente, Torrente 2: Misión en Marbella) y sólo si proceden de Estados Unidos o incluso Argentina tienen entidad como personajes femeninos desarrollados como sujetos en vez objetos..." (Argote, 2007:1).

En el siguiente tópico profundizo sobre la cuestión de la representación de las/os migradas/os. Pese a que ni los medios, ni la literatura sobre ellos, contemplen una perspectiva de género, en este apartado recojo algunas de las conclusiones respecto al tratamiento de la inmigración en general en los medios de comunicación, intentando integrar, en la medida de lo posible dado a la escasez de fuentes, algunos apuntes sobre género.

\subsection{La representación de la inmigración y de los migrados en los medios de comunicación}

Las representaciones sobre las mujeres migradas - o más bien, en el discurso de los medios de comunicación, "inmigrantes" - es un tema poco tratado por la literatura que discute la representación de la inmigración y de los migrados en los medios de comunicación ${ }^{15}$. Cabría aquí la hipótesis de que tal ausencia se dé por el mismo proceso de invisibilización que, en otros medios académicos, hizo que durante mucho tiempo la inmigración fuera tratada desde el estereotipo del "inmigrante" varón. Sin embargo, aunque no deseche esta primera hipótesis, es bastante probable que este proceso también ocurra en los propios medios de comunicación, donde la tendencia a la generalización, a los estereotipos y a la

\footnotetext{
${ }^{15}$ Claro está, esta crítica se refiere a la bibliografía consultada. Se trata de un repertorio reducido, pero pienso que es significativo que entre más de 25 artículos ninguno analice género.
} 


\section{perifèria}

\section{Número 8, Junio 2008 \\ www. periferia. name}

recurrencia de imágenes como la de las llegadas en pateras en las costas españolas refuerza la idea de que los "inmigrantes" son en su mayoría varones. Esta primera constatación es bastante importante, puesto que la ausencia de una perspectiva de género ya es, en si misma, una política de género, nombradamente, de invisibilización y exclusión.

Como ya dicho anteriormente, la representación de la inmigración en los medios construye discursivamente el "inmigrante" en cuanto un "otro" "étnico-nacional"16, generalmente representado como pobre y peligroso (King \& Wood, 2001; Lorite García, 2004; Bastida, 2006). Otra característica bastante común a estos discursos es que tienden a ser generalizantes: las personas no son reconocidas como individuos, puesto que son concebidas a través de estereotipos nacionales o incluso continentales ${ }^{17}$. Las características atribuidas a la "cultura", al país, son atribuidas por extensión a los individuos, resumiendo muchas veces su identidad a un origen geográfico. De hecho, la generalización es tan sumamente constante en los discursos sobre el "otro", que casi todos los autores citados la consideran como una de las principales estrategias discursivas de las élites y de los medios de comunicación respecto a los grupos migrados (King \& Wood, 2001; Lorite García, 2004; Bastida, 2006). Además, tal estrategia de tomar el todo por la parte es complementada por la práctica de tomar la parte por el todo: muchas veces los casos generalizados son extremos y atípicos, y no son representativos del colectivo en cuestión. Es el caso, por ejemplo, de la presentación de algún acto delictivo cometido por un miembro de un grupo migrado. Muchas veces el acto delictivo es extrapolado a un mensaje que asocia dicho grupo y criminalidad $^{18}$, bien como $^{2}$ inmigración y criminalidad. Esta última asociación es particularmente reiterada por los medios, que, al insistir en la clasificación de los migrados como "ilegales", los

\footnotetext{
${ }^{16}$ No considero etnia igual a nacionalidad y ni nacionalidad igual a etnia, sin embargo, utilizo estos términos entre comillas para referirme a la tendencia que existe en estos discursos de confundir y superponer los dos conceptos. El concepto de etnicidad que utilizo en este trabajo es inspirado en Eriksen (1996) - en cuanto una identidad construida en el contexto inmigratorio - y en Gilroy (1993), para dar profundidad a tal definición, al recordarnos su complejidad y problematizar cuestiones de pertinencia, tradición, etc.

${ }^{17}$ Como es muy común en el caso de África, véase Bañón (en Bastida, 2006).

${ }^{18}$ Véase Riccio (en King \& Wood, 2001), sobre el caso de los senegaleses en Italia.
} 


\section{perifèria}

\section{Número 8, Junio 2008}

\section{www. periferia.name}

asocia continuamente a la trasgresión de la ley (King \& Wood, 2001; Lorite García, 2004; Bastida, 2006).

Maataoui (en Bastida, 2006) es un autor que subraya el proceso por el cual las representaciones colonialistas y exotizantes del pasado todavía siguen presentes en el inconsciente colectivo. Tales representaciones forman, en gran medida, parte de un consenso general y entran en sistema con un discurso anti-inmigración que viene siendo desarrollado actualmente en la Unión Europea.

En este contexto, las representaciones sobre el "otro" se fundamentan en esencialismos y en una concepción de las otras culturas (nótese la confusión entre cultura y país) como pobres, atrasadas y problemáticas, mientras que la cultura europea simboliza el desarrollo, la civilización, la riqueza, la democracia. Tal y como nos muestra Stolcke (1995), el discurso sobre la inmigración en Europa viene desarrollando ideológicamente una forma de discriminación que pasa a ser crecientemente justificada a través de lo que tal autora nombra como "fundamentalismo cultural". En este discurso, las culturas europeas y extracomunitarias pasan a ser concebidas como incompatibles y conflictivas, de manera que la xenofobia seria un sentimiento "natural" por parte de los europeos que quieren mantener su cultura y el orden y estabilidad social de sus países (Stolcke, 1995).

Este discurso viene impregnando tanto la retórica política como mediática (King \& Wood, 2001). En los titulares la inmigración aparece insistentemente como una "avalancha", una "inundación", un problema social grande y preocupante: los “ilegales" Ilegan a Europa en grandes cantidades (Lorite García, 2004). En este discurso, en que la representación del “inmigrante"19 como ilegal es fácilmente extrapolable a la asociación entre inmigración y criminalidad, la protección de la "pureza" de la cultura europea y la defensa de los "valores europeos" es una de las justificaciones para el control de fronteras y para las políticas de exclusión social de los migrados (Stolcke, 1995, King \& Wood, 2001, Bastida, 2006).

\footnotetext{
${ }^{19}$ Aunque el objeto de estudio de tal autor sea la representación de lo "árabe", de lo "islámico" y lo “musulmán" en los medios españoles.
} 


\section{perifèria}

\section{Número 8, Junio 2008}

www. periferia. name

Tales representaciones acaban por eclipsar la realidad y la diversidad del fenómeno migratorio, cumpliendo una función claramente ideológica en el discurso sobre la inmigración, tanto por ser más mediático un criminal o una prostituta que un trabajador de la construcción civil o una camarera (Bastida, 2006) como por estar investida de intereses políticos (Stolcke, 1995). Nótese que, además de formar parte de un discurso acorde con los intereses del grupo dominante y el racismo de élite, los medios resaltan este tipo de representación sobre la inmigración por su necesidad de espectacularización de lo cotidiano (Bastida, 2006).

Respecto a las mujeres migradas, o bien éstas no existen, o bien no son sujetos en las representaciones de los medios de comunicación. Como bien observa Carracedo (2008): “...La mujer inmigrante en los medios es una víctima, sumisa, inculta, delincuente... Las mujeres inmigrantes protagonizan las noticias relacionadas con la violencia de género (lo que además contribuye a aumentar la criminalización de los varones inmigrantes), con la prostitución o la inmigración ilegal...". La invisibilidad de las mujeres migradas en los medios de comunicación hace que la representación que es hecha de ellas aparezca en gran medida como una extensión pasiva de la representación criminalizante atribuida a los migrados.

Desgraciadamente, por la escasez de la documentación sobre la representación audiovisual de las mujeres migradas, nos quedamos con relativamente pocos datos para analizar el siguiente caso de las migradas brasileñas en los medios de comunicación portugueses. Sin embargo, tenemos algunas buenas pistas a utilizar como herramientas, es decir, tenemos una serie de elementos a contrastar con el material a analizar, entre ellos, que la representación de las mujeres migradas tiende a presentar la asociación de éstas con la pobreza, la criminalidad, la ignorancia, la prostitución; a dotes especiales en el trato con los otros, a una idea racializada y exoticizada y a veces sexualizada de femineidad, a indocumentación, etc. Retengamos estas ideas en mente para el análisis que sigue. 


\section{perifèria}

Número 8, Junio 2008

www.periferia.name

\section{Un breve estudio de caso: la representación de las mujeres brasileñas en los medios de comunicación portugueses}

En este apartado, analizo como las imágenes sobre las mujeres brasileñas en los medios de comunicación portugueses reproducen tales tópicos sobre exotismo y sensualidad, representando las migradas brasileñas como portadoras de una sexualidad exacerbada y asociándolas a la prostitución ${ }^{20}$.

Un ejemplo de las imágenes de "mujer brasileña" que circulan en Portugal surge en el contexto de introducción de un producto brasileño en el mercado portugués, el Guaraná Brasil $^{21}$. En la publicidad ${ }^{22}$ queda claro que la carga simbólica accionada en la identificación del producto (guaraná) con el país (Brasil) es la de la exotización. En los anuncios vemos tucanes, mujeres y fútbol, y es en esta asociación que es creada una imagen sexualizada de la mujer brasileña: la modelo siempre es presentada en unos shorts de dimensiones reducidas, ropa verde-amarilla, jugando un fútbol erótico. En el anuncio principal de la campaña publicitaria la protagonista, después de beber guaraná, marca un gol y lo celebra subiéndose la camiseta y exhibiendo la ausencia de sujetador.

Existe una fuerte asociación entre género y nacionalidad en las representaciones de la mujer brasileña en los medios de comunicación portugueses. Sugiero que tales representaciones feminizan Brasil, al mismo tiempo que sexualizan género. Mientras según McClintock (1995), los procesos de feminización de la representación de la nación se encuentran relacionados con la historia del imperialismo y colonialismo, comportando procesos de racialización y erotización de la desigualdad, Piscitelli (2001) defiende que también están relacionados con las dinámicas contemporáneas de globalización y masificación del turismo internacional, en que la mujer brasileña es percibida por los extranjeros como portadoras de un cuerpo, de maneras y de una sexualidad diferentes. Todos estos

\footnotetext{
${ }^{20}$ No es mi intención negar la existencia de la prostitución de inmigrantes brasileñas en Portugal, sin embargo, el interés de este artículo se centra en cómo esta representación se desarrolla.

${ }^{21}$ Nótese que en Brasil el producto se llama Guaraná Antarctica.

22 Realizada por la agencia de publicidad BBDO Portugal.
} 


\section{perifèria}

\section{Número 8, Junio 2008}

\section{www. periferia.name}

procesos tienen como escenario las relaciones desiguales entre países, en que las relaciones "centro-periferia" se expresan en el campo simbólico en representaciones de tropicalidad y exotismo, en que las diferencias en el desarrollo y distribución de la riqueza son sensualizados, identificados de forma ambivalente con el ocio, la inactividad, la corporalidad, etc.

Durante mi trabajo de campo, ocurrió un episodio que explicitó muy bien todas estas cuestiones: en Bragança, un pueblo situado al nordeste de Portugal, un grupo de mujeres portuguesas, después de descubrir que sus maridos frecuentaban clubes de alterne en los cuales las brasileñas estarían sobre-representadas, enviaron a las autoridades locales un manifiesto reivindicando la expulsión de las prostitutas brasileñas/inmigrantes ilegales (nótese el salto discursivo y la confusión de conceptos entre inmigrante/inmigrante ilegal/trasgresor). Tal suceso se transformó en un episodio de grandes dimensiones mediáticas, llegando a ser portada de la edición europea de la revista Time.

Las mujeres portuguesas se auto-denominaron "As mães de Bragança" (literalmente, Las Madres de Bragança). Es especialmente significativo tal acto de bautismo, en que las esposas se posicionan en una des-sexualización del rol femenino y adoptan la perspectiva de una sexualidad materna, legítima y reproductiva, asociada a la domesticidad, cuidado de los hijos, etc. (Rosaldo, 1974). Si, de una parte, las que protestaban fueron luego asociadas a los atributos femeninos propios de la "Madre" (opuesto complementario de la imagen de prostitutas atribuida a las mujeres brasileñas), a las brasileñas les fueron atribuidas las connotaciones de vida disoluta, codicia, vanidad, sexualidad voraz y amenazadora, corruptora del orden social.

La siguiente imagen fue sacada del número 554, del 16-10-2003, de la revista portuguesa Visão. En ella, vemos el pie de foto: “BRASILEÑAS: su llegada cambió Bragança”. En el cuerpo del texto, citando la revista Time, el artículo habla de “...el surgimiento reciente de centenares de "chicas" mulatas, con poca ropa y extremamente disponibles..." y se compara lo sucedido con las telenovelas brasileñas Gabriela Cravo e Canela, Roque Santeiro y Tieta. 


\section{perifèria}

Número 8, Junio 2008

www. periferia. name

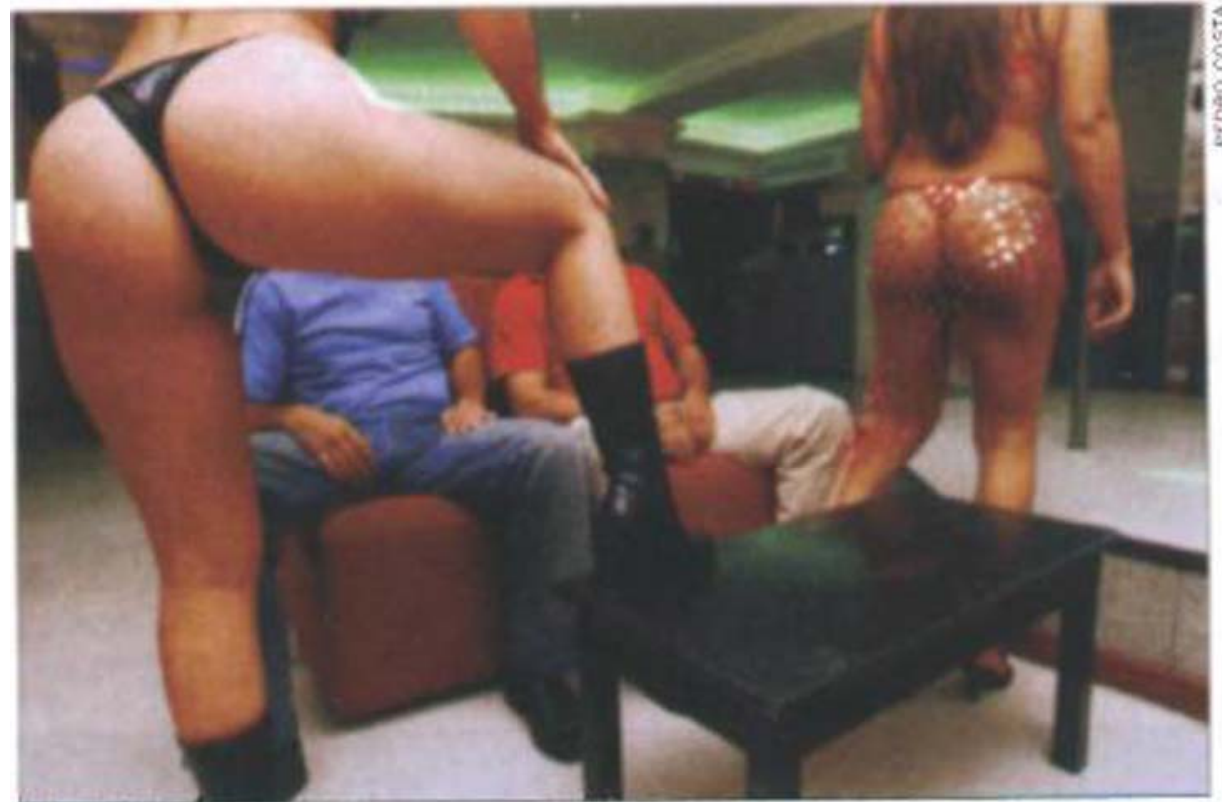

BRASILEIRAS A sua chegada mudou Bragança

Fonte: revista Visào. 16-10-2003.

Fuente: Revista Visão, 16-10-2003.

El artículo habla básicamente del tema de la sexualidad ilegítima practicada por exóticas morenas particularmente sensuales de los trópicos brasileños. En él, uno de los principales adjetivos utilizados para calificar a las brasileñas será el de mulata. Como hace notar Corrêa (1996), la figura de la mulata es construida a través de la asociación entre "raza" y género en la creación de estereotipos sexualizados relacionados a la identidad nacional brasileña. La mujer brasileña es asociada a la morenidad, samba y sensualidad, en una construcción ideológica que naturaliza la asimetría de las relaciones sociales de género, clase y etnicidad.

La comparación entre las migradas brasileñas y el personaje de Gabriela también es muy significativa. Almeida (2000), al comentar el impacto de la obra de Jorge Amado y su divulgación televisiva en Portugal explica cómo, a partir de la primera telenovela brasileña en la televisión portuguesa, Gabriela, exhibida en 1977, novelas y Gabriela se volvieron inseparables de las representaciones sobre el Brasil, 


\section{perifèria}

\section{Número 8, Junio 2008}

\section{www. periferia. name}

así como reedificaron el sentido común de las relaciones sociales de género y "raza". La popularidad de Gabriela es un símbolo de la recurrencia de las imágenes de una corporalidad sensual y amoral en la representación de la mujer racializada. Según el autor, la mujer pobre no blanca es producto de una hibridización cuyas líneas de poder son camufladas en una retórica de los afectos y de los sentidos, que esencializa las diferencias como justificación para la desigualdad: “...Triplemente subalterna, triplemente objeto de deseo: por mujer, por no blanca, por de las clases populares..."; sensual, sensorial, exótica, la mulata brasileña es “...una construcción estética que enmascara el proceso político de su construcción..." (Almeida, 2000: 39).

Así vemos un proceso de etnización de la nacionalidad ${ }^{23}$, lo cual es intensificado en el fenómeno migratorio. La clandestinidad y la ilegitimidad son atributos recurrentes en la representación de la inmigración en general, sin embargo, tienen connotaciones específicas en el caso de las/los migradas/os brasileñas/os. Como nota Machado (2003), en las representaciones corrientes en Portugal existe una fuerte asociación entre los/as brasileños/as y la estafa, de manera que el autor afirma que el parámetro de las representaciones de los/as brasileros/as es el binomio sexo/pillería, en que jugadores de fútbol y prostitutas son los tipos estructurales a partir de los cuales son representados los/as brasileños/as. En este proceso, las concepciones esencializadas de la cultura determinan la percepción de los individuos y, los tópicos de exotismo y sensualidad, atribuidos al carácter nacional brasileño, pasan a serlo en las mujeres brasileñas en general y a las migradas de esta nacionalidad radicadas en Portugal en particular.

La etnización de las mujeres migradas brasileñas está asociada al hecho de ser migradas $y$, por tanto, de pertenecer a otro grupo étnico-nacional exótico, periférico, racializado y de una clase económica subalterna. La etnicidad, en este caso, surge relacionada al papel social de "inmigrante" de un país tropical del

23 La noción de etnicidad aquí empleada se basa en Eriksen (1997) y se refiere a una identidad construida en el contexto migratorio. 


\section{perifèria}

\section{Número 8, Junio 2008}

\section{www. periferia.name}

"Tercer Mundo", que comprende 1) una imagen colonial24; 2) la historia de la inmigración portuguesa en Brasil; 3) la reciente inmigración brasileña en Portugal; 4) la construcción de una representación tropicalizante de Brasil; 5) un discurso del legado de la cultura portuguesa en los países de lengua portuguesa reminiscente de la retórica imperial; 6) la actual construcción ideológica de Portugal en cuanto país del "Primer Mundo" (con la adhesión a la Comunidad Europea) en oposición al "Tercer Mundo" (donde estaría ubicado Brasil).

Como vemos, los procesos de exotización y sexualización están asociados a un conjunto de concepciones acerca de la identidad nacional brasileña. Los principales tópicos que pueden ser verificados acerca del carácter nacional brasileño circulan alrededor del fútbol, del carnaval y de la samba, del mestizaje, de la alegría y de la sensualidad. Estos tópicos son irradiados desde el propio Brasil, por parte de los discursos estereotipados de identidad nacional y de las oficinas de turismo que intentan capitalizar la imagen tanto de las playas, como de las mujeres poco vestidas en ellas. Sin embargo, mientras en los discursos oficiales brasileños la violencia, la pobreza y las chabolas son omitidos, para el público internacional (así como para la propia élite brasileña) son los otros tópicos máximos complementarios acerca de Brasil que son fundamentales en la construcción de las representaciones de la cultura brasileña. Como hemos visto, tal aspecto "tercermundista" gana especial importancia en el contexto de las migraciones transnacionales.

Así, vemos como las imágenes en los medios de comunicación portugueses, a través de la construcción de la imagen de la mujer brasileña como exótica, racializada, con una moralidad tropical más bien laxa y dudosa, reproducen concepciones del otro que ya comentamos en el primer apartado de este artículo. Estas concepciones del otro vienen siendo criticadas desde hace algún tiempo y, en el próximo apartado, me dedico a concluir este trabajo mostrando alternativas a esta manera de representar el otro.

\footnotetext{
24 Distinta de una relación colonial como la establecida con la migración africana en Portugal, sino
} regida por una idea de Brasil como tercer mundo. 


\section{perifèria}

Número 8, Junio 2008

www. periferia. name

\section{Estrategias auto-reflexivas: propuestas para evadir la difusión de estereotipos}

Como hemos visto, la concepción de la imagen como "espejo de lo real" va ser un importante elemento en los usos naturalizantes e ideológicos de los medios audiovisuales. Algunas de las características más importantes del cuestionamiento de las convenciones tradicionales del documental, del cine etnográfico y otros productos audiovisuales afines se vuelca hacia: 1) la crítica al ocultamiento de las condiciones de producción de las películas; 2) la crítica a la autoridad etnográfica y 3) los problemas éticos que supone la representación del "otro".

Respecto al ocultamiento de las condiciones de producción de las películas, retomo aquí el ya citado ejemplo de la crítica de Rony (1996) a Flaherty. Esta autora recuerda que Nanook (1922) es una obra que fue presentada al público como la reproducción de una realidad auténtica, ocultando aquellas características del estilo de vida de los pueblos retratados que no convenían a su representación exoticizada. Es decir, los I nuit se encontraban en contacto con la cultura occidental desde hacía mucho y presentaban innegables índices de este contacto, los cuales son sistemáticamente negados por el producto audiovisual (por ejemplo, se escondían las armas de fuego de los nativos, presentándolos en peligrosas escenas de caza con sus armas tradicionales, etc.).

En lo tocante a la crítica a la autoridad etnográfica del realizador, esta es cuestionada en la medida en que queda explícito que la concepción de la imagen como "espejo de lo real" permite que la opinión el director sea transmitida como una verdad imparcial y objetiva, omitiendo su posicionamiento como sujeto histórico (Nichols, 1991). De otra parte, la representación del "otro" en la pantalla, la cuál siempre estuvo anclada en estas concepciones de verdad, imparcialidad, objetividad y cientificidad, muchas veces fue un lugar privilegiado de emisión juicios etnocéntricos y proyección de imágenes exoticizantes, convirtiendo el "otro" en espectáculo etnográfico (Nichols, 1991, Rony, 1996). 


\section{perifèria}

\section{Número 8, Junio 2008}

www. periferia. name

Uno de los precursores más importantes en este cambio será Jean Rouch. Según Feld (2003): “...Les maîtres fous fue su primera desviación de un cine puramente descriptivo hacia un abordaje mucho más sintético de las estructuras de los eventos. Habiendo observado un ritual muchas veces, se dio cuenta de que podía desmenuzar los aspectos cruciales y abordarlos como una narrativa..." (Feld, 2003: 5). Así, usando el montaje para crear conexiones contextualizantes y sacando el máximo provecho incluso de las limitaciones técnicas, Rouch fue capaz de superar el mero registro de los hechos y pasar a una realización más crítica y personal.

Tales cuestiones quedarían todavía más explícitas en 1960, cuando Rouch y Morin realizan Chronique d'un été. Esta película enseña parte de su proceso de producción y negociación con los personajes y también vemos los propios realizadores como personajes. Al final de la película, los participantes asistían como espectadores a las entrevistas filmadas anteriormente y debatían cuestiones tales como de qué forma la cámara afectaba la reacción de las personas, hasta qué punto el contenido de la película había sido incentivado y extraído por los cineastas, en qué sentido la película seria una "verdad-cinematográfica" y de qué forma sería algo más cercano a una película de ficción. Aunque ni participantes ni cineastas lleguen a una conclusión, todas estas cuestiones pasan a consistir en parte de los interrogantes fundamentales del cine de no ficción.

Actualmente ya no es raro encontrar películas que mezclen géneros y, aunque éste sea un momento en que presenciamos una mayor dificultad de clasificación debido a la heterogeneidad de la producción, podemos ver algunos puntos de convergencia general. Uno de ellos, por ejemplo, es el hecho de que el proceso de producción de la película, la negociación con los personajes y el posicionamiento del director ganan cada vez más espacio, hasta muchas veces convertirse en el tema de la propia película, como vemos en Roger y Yo, de Michael Moore.

Otra característica bastante recurrente es un registro más personal, en que el autor asume el interés del tema para él, cual es su implicación e, incluso, detalles personales de su propia biografía pueden ser vistos en pantalla. Tal y como en otros contemporáneos como Alan Berliner y su Nobody's Business, en Les Glaneurs et la Glaneuse, de Agnès Varda, vemos un ejemplo de película que incorpora la 


\section{perifèria}

Número 8, Junio 2008

\section{www.periferia.name}

subjetividad de la autora. En las palabras de Weinrichter: “..Soberbio ejemplo de (...) cinescritura, "Les Glaneurs..." parece seguir el libre curso del pensamiento de su autora en torno a un tema sobre el que ensaya una reflexión intercalando digresiones sobre sí misma y su vejez..." (Weinrichter, 2005:141). El reconocimiento de esta subjetividad, además de añadir contenido poético a las películas, deja muy claras las cuestiones de quién está hablando de qué y desde dónde, o sea, acaban por definir claramente la perspectiva, cuestión epistemológica tan cara a la Antropología contemporánea.

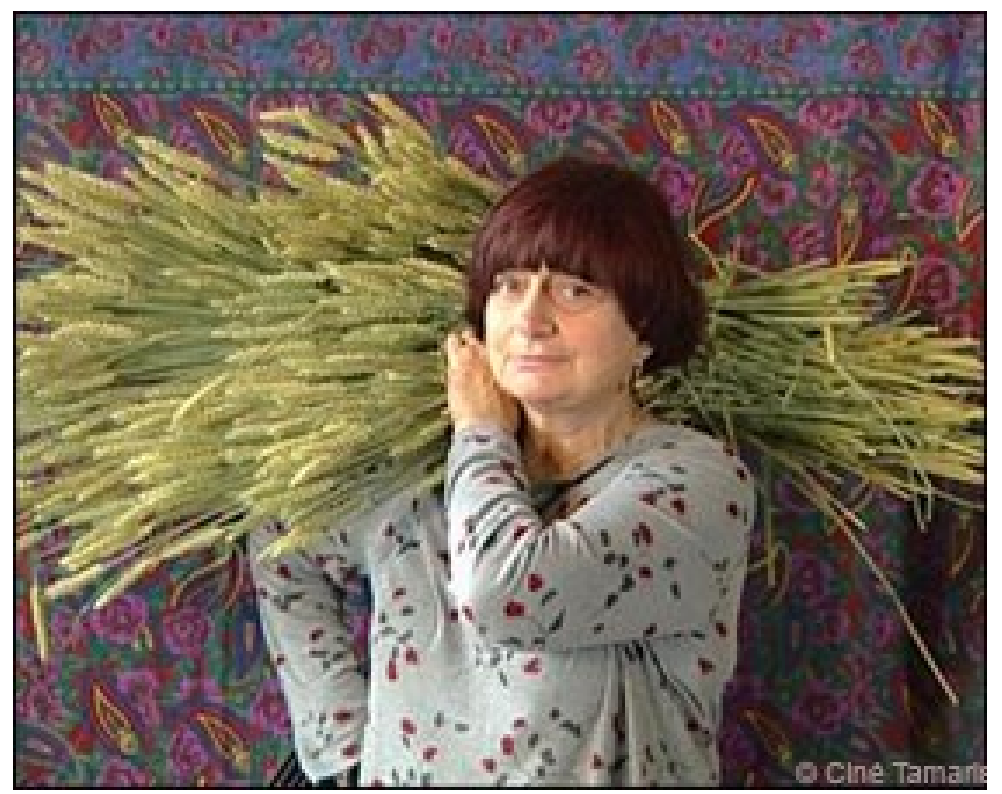

Fuente: $\underline{w w w . v i l l e t t e . c o m}$

\section{Conclusión}

En este artículo intenté mostrar, basándome en la historia del cine y de la fotografía y a través de ejemplos de mi propio trabajo de campo, cómo la representación del otro muchas veces ha sido sesgada por una mirada etnocéntrica, en que la imagen era incapaz de cumplir otra función que la difusión de tópicos y prejuicios. Sin embargo, existen muchas formas de producir imágenes, y, en la sección final de este trabajo, he procurado dar ejemplos de alternativas que, a través de la manipulación consciente de los medios Visuales y de la toma de posición, son 


\section{perifèria}

\section{Número 8, Junio 2008}

\section{www. periferia. name}

capaces de ultrapasar el etnocentrismo puro y duro.

Actualmente, la concepción de la imagen fotográfica o fílmica como un registro exacto de lo real ha sido criticada y, así como la etnografía, pasa a ser vista desde un punto de vista parcial de una realidad contestada y plural. Esta ruptura con la concepción documental de la imagen viene acompañada por una serie de cuestionamientos sobre la producción de la imagen y, entre otras características, intenta: 1) "dar voz" a aquellos quienes son representados y a su propia manera de mirar el mundo, 2) deconstruir discursos y crear narrativas menos cerradas y omniscientes, 3) cuestionar la autoridad y la invisibilidad del autor y 4) reconocer la subjetividad del realizador. Como he argumentado, encuentro particularmente interesante este último punto, el cual considero fundamental para la Antropología.

\section{Bibliografía}

Almeida, Miguel Vale de Almeida (2000). Um mar da cor da terra: raça, cultura e política da identidade. Oeiras: Celta Editora.

Argote, Rosabel (2003) La mujer inmigrante en el cine español del inaugurado siglo $X X I$. Feminismo/s, no2, Alicante.

Barnouw, Erik (1983) Documentary: a history of the non-fiction film. Oxford: Oxford University Press.

Barsam, Richard Meran (1974) Nonfiction film: a critical history. London: George Allen \& Unwin Ltd.

Bastida, Manuel Lario et al. (2006). Medios de comunicación e inmigración. Murcia: Caja de Ahorros del Mediterráneo.

Pérez Carracedo, Lola (2008) Obstáculos y oportunidades para mejorar la cobertura de la inmigración en femenino en los medios. [En linea] Mujeres en Red, vol. 32, 1, enero de 2008. Página web de revista electrónica. <http://www. mujeresenred.net/spip.php?article1058> [Consulta, 05 de abril de 2008].

Corrêa, Mariza (1996) A Invenção da Mulata, Cadernos Pagu, 6/7, Campinas.

Costa, Pedro (2003) Fotografía de prostitutas brasileñas en Bragança. (2003). Revista Visão, 554, Lisboa.

Dubois, Philippe (1986) El acto fotográfico. De la representación a la recepción. Barcelona: Paidós.

Eriksen, Thomas (1997) Ethnicity, race and nation en The Ethnicity Reader: 


\section{perifèria}

\section{Número 8, Junio 2008 \\ www.periferia. name}

Nationalism, Multiculturalism and Migration. Cambridge: Polity Press.

Ewing, William A. (1994) The body: photographs of the human form. Chronicle Books: San Francisco.

Feld, Steven, editor y traductor (2003) J ean Rouch Ciné-ethnography. Minneapolis: University of Minnesota Press.

Freund, Gisèle (2006) La fotografía como documento social. Barcelona: Editorial Gustavo Gili, SL.

Gilroy, Paul (1993) The Black Atlantic: Modernity and double consciousness. Cambridge: Harvard University Press.

Gregorio Gil, Carmen (2002) "Procesos migratorios y desigualdad de género" en Cuestiones de género en el fenómeno de las migraciones. Madrid: Universidad Pontificia Comillas, pp. 11-38.

Hayward, Susan (1996 [2006]) Cinema Studies. The Key Concepts. London \& New York: Routledge.

Hartmann, Wolfram; Sylvester, J.; Hayes, P. eds. (1998) The Colonising Camera. Photographs in the Making of Namibian History. Cape Town: University of Cape Town Press.

Heider, Karl (1995) Uma história do filme etnográfico. Cadernos de Antropologia e I magem, 1, Rio de J aneiro.

Lorite García, Nicolas et al. (2004). Tratamiento informativo de la inmigración en España. 2002. Madrid: Ministerio de Trabajo y Asuntos Sociales.

King, Russel y Wood, N., ed. (2001). Media and Migration: Constructions of mobility and difference. London: Routledge.

Luís, Filipe (2003). O país dos escândalos sexuais. Revista Visão, 554, Lisboa.

Machado, Igor José Reno de (2003). Cárcere Público: processos de exotização entre imigrantes brasileiros no Porto, Portugal. Campinas: Tese de Doutorado UNICAMP.

McClintock, Anne (1995) Imperial Leather: race, gender and sexuality in the colonial contest. London: Routledge.

Mulvey, Laura (1975) Visual Pleasure and Narrative Cinema. Screen, 16 (3), London.

Mulvey, Laura (2001) Unmasking the gaze: some thoughts on new feminist film theory and history. En Lectora, 7, Barcelona.

Nash, Mary (2006) Identidades de género, mecanismos de subalternidad y procesos de emancipación femenina. Revista CIDOB d'Afers Internacionals, 73-74, Barcelona.

Nichols, Bill (1991) Representing Reality: Issues and Concepts in Documentary. Bloomington: Indiana University Press.

Ortner, Sherry B. (1996) Making gender. The politics and erotics of culture. Boston: 


\section{perifèria}

Número 8, Junio 2008

www.periferia. name

Beacon Press.

Parella Rubio, Sonia (2003) Mujer, inmigrante y trabajadora: la triple discriminación. Rubí (Barcelona): Anthropos Editorial.

Piscitelli, Adriana (2004) On "gringos" and "natives": gender and sexuality in the context of international sex tourism in Fortaleza, Brazil". Vibrant, 1 (1), Brasília.

Ripley, Amanda (2003) When the Meninas Came to Town. Time Magazine, 162 (15), London.

Rodrigo Alsina, Miguel (2006) Posmodernidad y Crisis de Identidad. Revista Científica de Información y Comunicación, 3, Sevilla.

Rony, Fatimah Tobin (1996) The Third Eye. Race, cinema, and ethnographic spetacle. Durham: Duke University Press.

Rosaldo, Michele y Lamphere, L., ed. (1974). Women, Culture and Society. Stanford: Stanford University Press.

Rose, Gillian (2001) Visual methodologies. London: Sage Publications.

Rosenstone, Robert A. (1997) El pasado en imágenes. El desafío del cine a nuestra idea de la historia. Barcelona: Editorial Arial.

Sipi, Remei y Araya, M. (2005) Les Dones Migrades: apunts, històries, reflexions, aportacions... Barcelona: Institut Català de les Dones.

Stolcke, Verena (1995). Talking Culture: New Boundaries, New Rethorics of Exclusion in Europe. Current Anthropology, 36 (1), Chicago.

Weinrichter, Antonio (2004) Desvíos de lo real. El cine de no ficción. Madrid: T\&B editores.

\section{Filmografía}

Título: Chang

Director: Merian C. Cooper y Ernest B. Schoedsack

Nacionalidad: Estados Unidos

Año: 1927

Duración: 1h. 09min.

Lengua: Inglés

Título: Congorilla 


\section{perifèria}

Número 8, Junio 2008

www. periferia. name

Director: Martin E. Jonson, Osa J ohnson

Nacionalidad: Estados Unidos

Año: 1932

Duración: 67 min.

Lengua: inglés

Título: Chronique d'un été

Director: Jean Rouch y Edgar Morin

Nacionalidad: Francia

Año: 1960

Duración: 90 min.

Lengua: Francés

Título: Grass

Director: Merian C. Cooper y Ernest B. Schoedsack

Nacionalidad: Estados Unidos

Año: 1925

Duración: 71 min.

Lengua: muda con intertítulos en inglés

Título: Jaguar

Director: Jean Rouch

Nacionalidad: Francia

Año: 1954

Duración: 91 min.

Lengua: francés

Título: Les maîtres fous

Director: Jean Rouch

Nacionalidad: Francia

Año: 1955

Duración: 30 min. 


\section{perifèria}

Número 8, Junio 2008

www. periferia. name

Lengua: francés

Título: Les glaneurs et la glaneuse

Director: Agnès Varda

Nacionalidad: Francia

Año: 2000

Duración: $78 \mathrm{~min}$.

Lengua: francés

Título: Nanook of the North

Director: Robert Flaherty

Nacionalidad: Estados Unidos, Francia

Año: 1922

Duración: $79 \mathrm{~min}$.

Lengua: muda, intertítulos en inglés

Título: Nobody's business

Director: Alan Berliner

Nacionalidad: Estados Unidos

Año: 1996

Duración: 60 min.

Lengua: inglés

Título: Petit a Petit

Director: J ean Rouch

Nacionalidad: Francia

Año: 1971

Duración: 96 min.

Lengua: francés 


\section{perifèria}

Número 8, Junio 2008

www. periferia. name

Título: Roger y yo

Director: Michael Moore

Nacionalidad: Estados Unidos

Año: 1989

Duración: 87 min.

Lengua: inglés

Título: Tarzan de los monos

Director: W.S. Van Dyke

Nacionalidad: Estados Unidos

Año: 1932

Duración: 99 min.

Lengua: inglés 